\title{
EFFECT OF PYRROLE DERIVATIVE ON THE RAT COLONIC MUCOSA COMPARED TO 5-FLUOROURACIL
}

\author{
Maryna Yena \\ Department of Normal Physiology, Biophysics, Biochemistry and \\ Medical Biology \\ Kyiv Medical University of UAFM \\ 9 Leo Tolstoy str., Kyiv, Ukraine, 01004 \\ yenamaryna.7@gmail.com \\ Nataliya Dzyubenko \\ Research sector "Membranology and Cytology" \\ Educational and Scientific Centre "Institute of Biology" \\ Taras Shevchenko National University of Kyiv \\ 64/13 Vladimirskaya str., Kyiv, Ukraine, 01601
}

\begin{abstract}
Prevention the development of malignant tumors and treatment of cancer patients remains an important problem today. In spite of substantive progress in the cancer diagnostics and treatment cancer occupies one of the main places in human morbidity and mortality in the World. Targeted therapy is an alternative to traditional one through targeted action on tumor cells and relatively low toxicity. Inhibitor of membrane tyrosine kinases dihydropyrrole derivative 5-amino-4-(1,3-benzothiazole-2-yl)-1-(3-methoxyphenyl)-1,2-dihydro-3H-pyrrol-3-one (D-1) has significant antitumor activity on colorectal cancer and low toxicity acting in effective dose. However, to assess the D-1 therapeutic gap the investigation of its higher doses is necessary.

The investigation was aimed at D-1 effects applied at different doses compared to 5-fluorouracil one on rats ascending colon mucosa.

The research has found out that the dihydropyrrole derivative has no damaging effect on the colon of rats, whereas the administration of 5-fluorouracil causes marked mucosal lesion of the ascending colon. Hereby D-1 low toxicity to ascending colon mucosa compared to 5-FU and wide therapeutic gap of the first was concluded.
\end{abstract}

Keywords: intestinal mucosa, dihydropyrrole derivative, 5-fluorouracil.

\section{Introduction}

In recent years there has been a fairly high level of digestive system cancer, which tends to increase. This remains a topical issue in modern medicine. Often one of the causes of cancer is impaired tyrosine kinase activation processes, which regulates the different stages of growth and proliferation of cells $[1,2]$. Therefore, a promising trend in modern medicine is associated with targeted highly selective medicinal products, in particular membrane tyrosine kinase inhibitors characterized by high antitumor activity and lower toxicity as compared with traditional cytostatics [3-6]. Medicinal products in this class include dihydropyrrole derivative 5-amino-4-(1,3-benzothiazole-2-yl)-1-(3-methoxyphenyl)-1,2-dihydro-3H-pyrrol-3-one (D-1) in silico synthesized at Research and Production Biochemical Center of Taras Shevchenko National University as targeted inhibitors of protein kinase, which due to the spatial structure of the molecule interacts with the ATP-binding centre of tyrosine protein kinases and is their effective blocker [7-9]. Since the cytotoxic effect of the medicinal product D1 has been demonstrated on the transformed lines [7, 8, 10] and cancer cells [11], it is said to be a potential compound for use in clinical practice [12-14].

\section{Aim of research}

The aim of the research was to evaluate the effect of different doses of dihydropyrrole derivative (D1) on the rectal mucosa of rats compared to the traditional chemotherapeutic agent 5-fluorouracil (5-FU). 


\section{Materials and Methods}

\section{1. Experimental Animals}

The studies were conducted on 90 white mongrel male rats with an average body weight of $90 \pm 108 \mathrm{~g}$. The rats were housed under standard environmental conditions $\left(23 \pm 1^{\circ} \mathrm{C}, 55 \pm 5 \%\right.$ humidity and a 12-h light: 12-h dark cycle) and maintained with free access to water and a standard laboratory diet ad libitum

The study was conducted in accordance with the generally accepted bioethical standards of humane treatment of laboratory animals, in accordance with national and international regulations on carrying out experimental tests ("European Convention for the Protection of Vertebrate Animals used for experimental and other scientific purposes" (Strasbourg, 1986), "General Ethical Principles of Animal Experiments", adopted by the First National Congress on Bioethics (Kiev, 2001).

\section{2. Grouping of experimental rats}

The rats chosen for the study were divided in the eight groups and each group was experimented as follows:

Group I: Rats of this group (control) were administrated oil containing $15 \%$ DMSO $(0.1 \mathrm{ml}$ in total).

Group II: Rats of this group were administrated D1 at the dose of $2.3 \mathrm{mg} / \mathrm{kg}$ (conventionally effective) dissolved in sunflower oil containing $15 \%$ DMSO $(0.1 \mathrm{ml}$ in total $)$ per os, which, under the conditions of complete absorption, creates blood concentration of $10^{-4} \mathrm{M}$.

Group III: Rats of this group were administrated D1 at the dose of $11.5 \mathrm{mg} / \mathrm{kg}$ (5-fold the effective dose) dissolved in sunflower oil containing $15 \%$ DMSO (0.1 $\mathrm{ml}$ in total) per os, which, under the conditions of complete absorption, creates blood concentration of $5 \times 10^{-4} \mathrm{M}$.

Group IV: Rats of this group were administrated D1 at the dose of $23 \mathrm{mg} / \mathrm{kg}$ (10 times the effective dose) dissolved in sunflower oil containing $15 \%$ DMSO (0.1 $\mathrm{ml}$ in total) per os, which, under the conditions of complete absorption, creates blood concentration of $10 \times 10^{-4} \mathrm{M}$.

Group V: Rats of this group were administrated $5-\mathrm{FU}$ at the dose of $0.86 \mathrm{mg} / \mathrm{kg}$ intraperitoneally, which, under the conditions of complete absorption, creates blood concentration $10^{-4} \mathrm{M}$.

Group VI: Rats of this group were administrated 5-FU at the dose of $4.3 \mathrm{mg} / \mathrm{kg}$ intraperitoneally, which, under the conditions of complete absorption, creates blood concentration $5 \times 10^{-4} \mathrm{M}$.

Group VII: Rats of this group were administrated 5-FU at the dose of $8.6 \mathrm{mg} / \mathrm{kg}$ (conventionally effective) intraperitoneally, which, under the conditions of complete absorption, creates blood concentration $10 \times 10^{-4} \mathrm{M}$.

Group VIII: Rats of this group were administrated 5-FU at the dose of $45 \mathrm{mg} / \mathrm{kg}$ (-fold the effective dose) intraperitoneally.

\section{3. Introduction of chemicals to rats}

The effect of dihydropyrrole derivative (D1 (a new compound, the drug is not in his nature)) at different doses, and its comparison with 5-FU effect on the morphological and functional condition of the rat colon were studied in the setting of short exposure (14 days). The test substance was administered daily on an empty stomach. D1 at the doses of $2.3 \mathrm{mg} / \mathrm{kg}$ (conventionally effective), $11.5 \mathrm{mg} / \mathrm{kg}$ (5-fold the effective dose) and $23 \mathrm{mg} / \mathrm{kg}$ (10 times the effective dose) was injected dissolved in sunflower oil containing $15 \%$ DMSO (0.1 $\mathrm{ml}$ in total) per os, which, under the conditions of complete absorption, creates blood concentration of $10^{-4} \mathrm{M}, 5 \times 10^{-4} \mathrm{M}$ and $10 \times 10^{-4} \mathrm{M}$ respectively. 5-FU (VEROPHARM OJSC, solution for intravascular administration) was administered intraperitoneally at the doses of $0.86 \mathrm{mg} / \mathrm{kg}$, $4.3 \mathrm{mg} / \mathrm{kg}, 8.6 \mathrm{mg} / \mathrm{kg}$ (conventionally effective), which, under the conditions of complete absorption, creates blood concentration $10^{-4} \mathrm{M}, 5 \times 10^{-4} \mathrm{M}, 10 \times 10^{-4} \mathrm{M}$ respectively, and $45 \mathrm{mg} / \mathrm{kg}$ (-fold the effective dose). Control animals received oil containing $15 \%$ DMSO $(0.1 \mathrm{~mL}$ in total). Animals were sacrificed 1 day after the last administration of the substances by $\mathrm{CO}_{2}$ inhalation followed by cervical dislocation. 


\section{4. Tissue preparation}

The histological examinations were performed using rectal segments, which were fixed in $10 \%$ neutral formalin saline, paraffin sections were prepared and stained with hematoxylin-eosin according to the standard procedure $[15,16]$. The preparations were analyzed at the light-optical level using the microscope Bresser Researcher Trino (100, 400 magnification) (Bresser, Germany), coloured microphotographs were obtained using the digital camera Delta Optical CCD HDCE 5.0 (Delta Optical, Poland) and the above mentioned microscope. The general condition of the rectal mucosa was evaluated, the relative amount of goblet cells and mitotic index of cells in the crypts were calculated. The morphometric study was conducted using WCIF ImageJ. The thickness of the mucosa, depth and width of crypts, height of colonocytes, sectional area of goblet cells and nuclei of colonocytes were measured.

\section{5. Statistical Analysis}

The treatment of the experimental data was carried out by methods of variation statistics [16] using the software package SPSS 16.0: the data were tested for normality of distribution using the Kolmogorov-Smirnov Z-test, intergroup comparison was performed by one-way analysis of variance (ANOVA) with the use of posteriori multiple comparisons of Bonferroni test, and using U-Mann-Whitney test. The difference between the values of the parameters was compared, it was considered significant at $\mathrm{p} \leq 0.05$.

\section{Results}

Rectal mucosa of rats in the control group had a typical histological structure characteristic of this type of experimental animals, with no signs of pathological processes (Fig. 1, d). Morphometric data are presented in Tables 1, 2.

Administration of 5-FU at the dose of $0.86 \mathrm{mg} / \mathrm{kg}$ resulted in lymph infiltration of the rectal mucosa, oedema, isolated conglomerations of lymphoid tissue in the submucosa, sometimes distorted crypts $($ Fig. 1, a). Compared with the control group no probable changes were observed (Table 1, 2).

5-FU at a dose of $4.3 \mathrm{mg} / \mathrm{kg}$ caused lymph infiltration and oedema of the lamina propria (Fig. 1, b). Compared with the control group significantly increased the relative number of crypts bifurcation $77 \%$ (Table 2), which is an indication of enhanced recovery.

Following the exposure to $5-\mathrm{FU}$ at the dose of $8.6 \mathrm{mg} / \mathrm{kg}$ in the rectal mucosa there was diffuse desquamation of the epithelial layer, lymph infiltration and oedema as well as dilation of blood capillaries and in the submucosa, sometimes proliferation of the lymphoid tissue (Fig. 1, c). The analysis of morphometric parameters showed significantly increased crypt depth by $24.7 \%$ (which is an adaptive response), height of colonocytes by $42.6 \%$ (which indicates certain strengthening of the functional activity of colonocytes), relative number of bifurcation crypts by $87.5 \%$ (which is a sign of enhanced regeneration) (Table 1, 2).

Table 1

Morphometric parameters of rectal mucosa of rats under the action of various doses of D1, 5-FU (M \pm SD)

\begin{tabular}{ccccc}
\hline & $\begin{array}{c}\text { Thickness of } \\
\text { the mucosa, } \boldsymbol{\mu m}\end{array}$ & $\begin{array}{c}\text { Depth of } \\
\text { crypts, } \boldsymbol{\mu m}\end{array}$ & $\begin{array}{c}\text { Width of } \\
\text { crypts, } \boldsymbol{\mu m}\end{array}$ & $\begin{array}{c}\text { Height of } \\
\text { colonocytes } \boldsymbol{\mu m}\end{array}$ \\
\hline Control & $680.9 \pm 99.0$ & $243.6 \pm 22.5$ & $31.2 \pm 3.8$ & $13.6 \pm 2.4$ \\
colonocyte nuclei, $\boldsymbol{\mu m} \mathbf{m}^{2}$
\end{tabular}




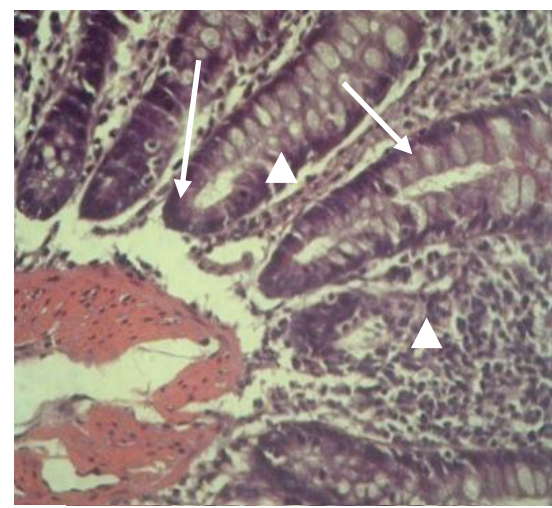

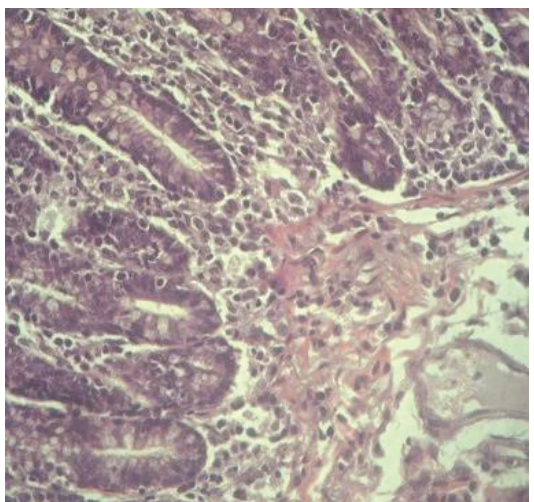

$b$
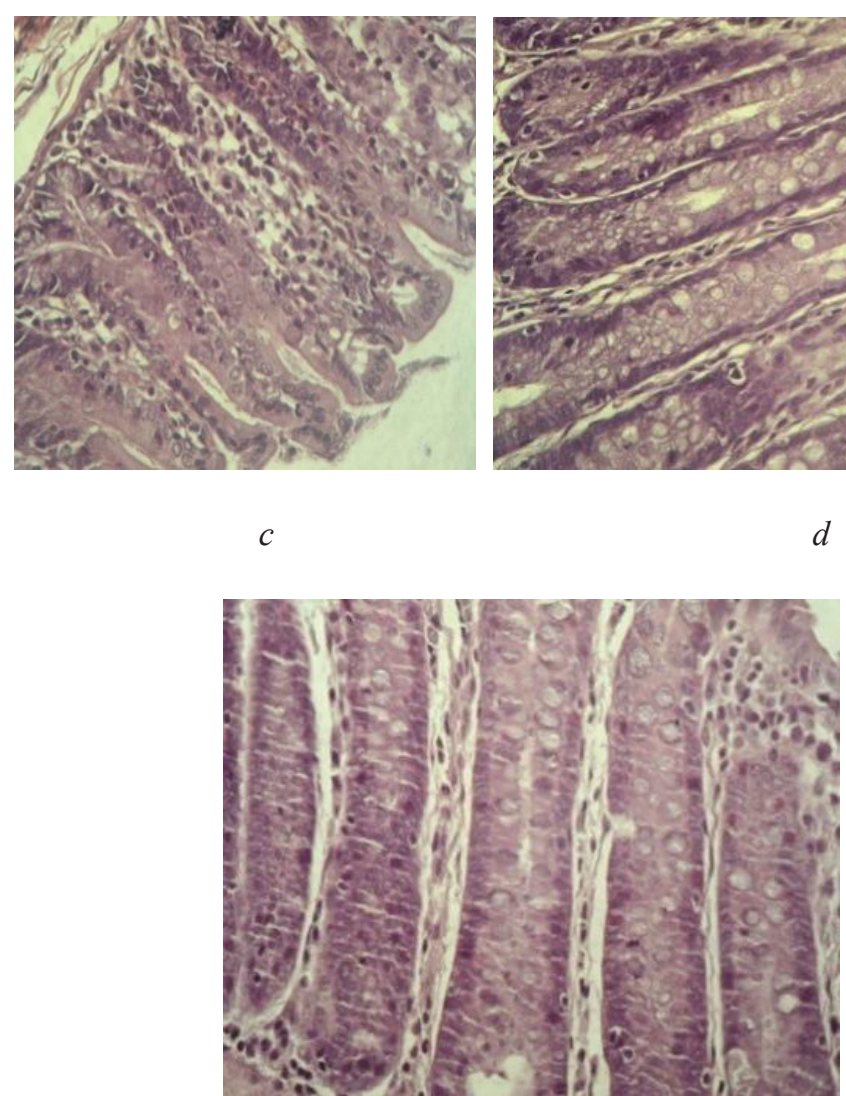

$f$

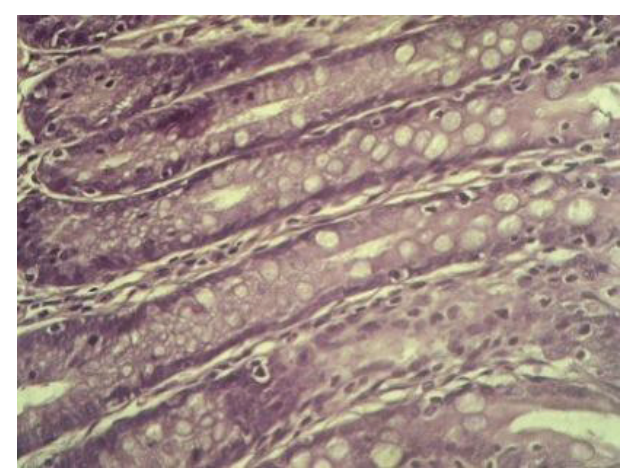

d

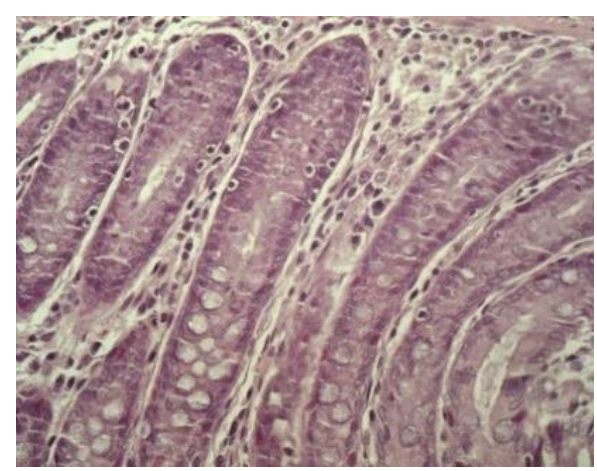

$e$

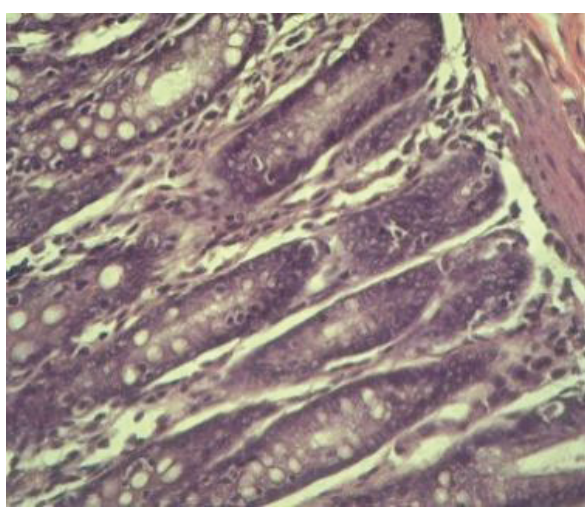

$g$

Fig. 1. Photomicrography of the rat colon sections after exposure to 5-FU and D1 at various doses: $a-5-\mathrm{FU}$ at the dose of $0.86 \mathrm{mg} / \mathrm{kg}$, accumulation of leukocytes (inset $\Delta$ ) and dense edema (arrowhead); $b-5-\mathrm{FU}$ at the dose of $4.3 \mathrm{mg} / \mathrm{kg}$, accumulation of leukocytes (inset $\Delta$ ) and mid edema (arrowhead); $c-5-\mathrm{FU}$ at the dose of $8.6 \mathrm{mg} / \mathrm{kg}$, accumulation of leukocytes (inset $\Delta$ ) and mid edema (arrowhead), diffuse desquamation of the epithelial (急); $d$-control; $e-\mathrm{D} 1$ at the

dose of $2.3 \mathrm{mg} / \mathrm{kg} ; f-\mathrm{D} 1$ at the dose of $11.5 \mathrm{mg} / \mathrm{kg}$, accumulation of leukocytes (inset $\Delta$ ); $g-\mathrm{D} 1$ at the dose of $23 \mathrm{mg} / \mathrm{kg}$, accumulation of leukocytes (inset $\Delta$ ), dense edema (arrowhead) and congestion of blood vessels $(\Xi), \times 400$, haematoxylin-eosin staining

Daily administration of 5-FU at the dose of $45 \mathrm{mg} / \mathrm{kg}$ (a weekly dose, 5 -fold the effective dose) caused the death of the whole experimental group by the end of the first week of the experiment. The animals experienced baldness, exhaustion, redness around the nose, inflammation of the 
mucous membranes of the eyes, autopsy of the dead rats showed ulcers in the digestive tract and intestinal obstruction.

The exposure to D1 at the effective dose $(2.3 \mathrm{mg} / \mathrm{kg})$ for 14 days caused no lesions of the rectal mucosa, except dilation of blood capillaries (Fig. 1, e). Morphometric parameters of the mucosa did not differ significantly from the control (Table 1, 2).

In animals exposed D1 at the dose 5-fold of the effective dose $(11.5 \mathrm{mg} / \mathrm{kg})$ for 14 days there was lymph infiltration of the lamina propria, muscle layer thickening (Fig. 1, $\boldsymbol{f}$ ). In the serous layer there was noticeable vasodilatation and filling of vessels with blood. Morphometric parameters of the mucosa did not differ significantly from the control (Table 1, 2).

The exposure to D1 at the dose 10 -fold of the effective dose of $(23 \mathrm{mg} / \mathrm{kg})$ for 14 days resulted in lymph infiltration of the lamina propria, oedema, sometimes vasodilatation, stasis of blood in the capillaries and minor bleeding (Fig. 1, g). Compared to the control there was an increase in the relative number of goblet cells by $35.8 \%$ (Table 2), which is a sign of the increased mucus production in the mucosa.

Table 2

Status of goblet cells and mitotic index of the rectum of rats exposed to various doses of D1, 5-FU (M \pm SD)

\begin{tabular}{cccc}
\hline & Goblet cell area, $\boldsymbol{\mu m}^{2}$ & $\begin{array}{c}\text { Relative number of } \\
\text { goblet cells, } \%\end{array}$ & $\begin{array}{c}\text { Relative number } \\
\text { of bifurcation crypts, } \%\end{array}$ \\
\hline Control & $77.9 \pm 44.4$ & $23.8 \pm 4.6$ & $5.8 \pm 1.1$ \\
D1 $2.3 \mathrm{mg} / \mathrm{kg}$ & $103.8 \pm 8.0$ & $23.0 \pm 10.0$ & $5.5 \pm 1.0$ \\
D1 $11.5 \mathrm{mg} / \mathrm{kg}$ & $90.4 \pm 5.5$ & $25.5 \pm 5.0$ & $6.0 \pm 4.0$ \\
D1 $23 \mathrm{mg} / \mathrm{kg}$ & $91.8 \pm 22.3$ & $24.0 \pm 2.0$ & $6.5 \pm 5.0$ \\
5 -FU $0.86 \mathrm{mg} / \mathrm{kg}$ & $108.5 \pm 76.7$ & $22.5 \pm 1.0$ & $7.5 \pm 1.0$ \\
5 -FU $4.3 \mathrm{mg} / \mathrm{kg}$ & $96.3 \pm 25.6$ & $21.5 \pm 7.0$ & $9.0 \pm 2.0$ \\
5 -FU $8.6 \mathrm{mg} / \mathrm{kg}$ & $119.1 \pm 15.4$ & $26.0 \pm 4.0$ & $7.0 \pm 2.0$
\end{tabular}

Note: ${ }^{*}-p \leq 0.05$ vs. control

\section{Discussion}

Thus, the effects of both cytostatics in the rectal mucosa in rats are increased dosedependently. 5-FU at the therapeutic dose did not lead to animal death $(0.86,4.3$ and $8.6 \mathrm{mg} / \mathrm{kg}-$ therapeutic), but caused desquamation of the epithelium, inflammation (as demonstrated by stroma oedema, its lymph infiltration and hyperaemia as well as proliferation of the lymphoid tissue as a source of $\mathrm{T}$ and B lymphocytes). An increased functional activity of colonocytes and regeneration are manifestations of adaptation processes. Such signs may indicate the development of drug acute catarrhal colitis [17].

5-FU at the doses below therapeutic efficacy has negative effects on the intestine. 5-FU at the dose 5-fold of the effective dose causes the death of animals with signs of exhaustion, ulcers of the gastrointestinal tract (GIT), constipation, hair loss. The reason for these phenomena is suppression of the proliferation of the gastrointestinal epithelium (as a result - impaired digestion and absorption, slime excretion, motility) and skin - side effects characteristic of cytostatic action $[4,9]$. Differing effects of various doses of 5-FU on the proliferation of progenitor cells of colonocytes and regeneration of mucosa can be explained by the different sensitivity of DNA and RNA synthesis to changes of the pool of nucleotides. RNA synthesis is more sensitive to the action of 5-fluorouracil (direct incorporation of 5-FU in the RNA molecule instead of uracil) [2, 4, 6], and therefore cells differentiation "suffers", which requires the expression of genes, and thus RNA synthesis. As a result, colonocytes in the crypts are immature and therefore, they age faster and are actively peeled requiring the active separation of predecessors to maintain the population of cells of the mucous membrane. DNA synthesis with replication is a more "protected", possibly through an indirect effect of 5-FU (need for the synthesis of thymidine), and through multiple repair systems, so it is inhibited when exposed to higher (effective) dose of 5-FU [4, 18-20]. 
D1, in contrast to 5-FU at the studied doses (relatively effective and higher) is low toxic to the colonic mucosa. So the signs of inflammation are observed during the exposure to the doses exceeding the effective 5 and 10 times. The proliferation of progenitor cells of colonocytes remains unaltered, intensity of the regenerating mucosa does not differ from physiological one. The findings indicate a fairly wide therapeutic window of D1, accordingly, its safety for the intestine, which is consistent with our previous data $[11,12,14]$.

\section{Conclusion}

1. Dihydropyrrole derivative 5-amino-4-(1,3-benzothiazole-2-yl)-1-(3-methoxyphenyl)-1,2dihydro-3H-pyrrol-3-one (D-1), in contrast to 5-FU, is a low toxic compound for the colon of rats when exposed to the doses 5 and 10 times higher than conventionally effective.

2. The effect of D1 studied doses are limited to the signs of inflammation and mild desquamation of the epithelium, in contrast to 5-FU, which leads to the development of drug colitis.

3. Proliferative activity of colonocyte progenitor cells and regeneration of the mucous membrane under the action of all D1 studied doses remain at the physiological level.

\section{References}

[1] Siegel, R., Ma, J., Zou, Z., Jemal, A. (2014). Cancer statistics, 2014. CA A Cancer Journal for Clinicians, 64 (1), 9-29. doi: 10.3322/caac.21208

[2] Di Gion, P., Kanefendt, F., Lindauer, A., Scheffler, M., Doroshyenko, O., Fuhr, U. et. al. (2011). Clinical Pharmacokinetics of Tyrosine Kinase Inhibitors. Clinical Pharmacokinetics, 50 (9), 551-603. doi: 10.2165/11593320-000000000-00000

[3] Kumar, M., Naqpal, R., Hemalatha, R., Verma, V., Kumar, A., Sinqh, S., Marotta, F., Jain, S., Yadav, H. (2012). Targrted cancer therapies: of future of cancer treatment. Acta Biomed, 83 (3), 220-233.

[4] Baudino, T. (2015). Targeted Cancer Therapy: The Next Generation of Cancer Treatment. Current Drug Discovery Technologies, 12 (1), 3-20. doi: 10.2174/1570163812666150602144310

[5] Garmanchuk, L. V., Denis, E. O., Nikulina, V. V., Dzhus, O. I., Skachkova, O. V., Ribalchenko, V. K., Ostapchenko, L. I. (2013). MI1 - derivative of maleimide inhibits cell cycle progression in tumor cells of epithelial origin. Biopolymers and Cell, 29 (1), 70-74. doi: 10.7124/bc.000808

[6] Tsai, C.-J., Nussinov, R. (2013). The molecular basis of targeting protein kinases in cancer therapeutics. Seminars in Cancer Biology, 23 (4), 235-242. doi: 10.1016/j.semcancer.2013.04.001

[7] Garmanchuk, L. V., Lynchak, O. V., Nikulina, V. V. et. al. (2013). Maleimide derivate 1-(4-Clbenzyl)-3-Cl-4-(CF3-phenylamino)-1H-pyrrole-2.5-dyon as an effective and low-toxic cytostatic drug. Experimental and clinical pharmacology, 8 (76), 39-42.

[8] Babuta, O., Kutuzova, N., Lynchak, O. (2013). The influence of maleimide derivative and 5-fluoracil on morphological state of the small intestine of rats with chemical-induced colon cancer. Bulletin of Kyiv National Taras Shevchenko University, 2 (64), 50-53.

[9] Byelinska, I. V., Ostrovska, G. V., Dyagil, I. S., Rybalchenko, V. K. (2010). Hematological effect of proteinkinases inhibitor maleimidederivative (1-(4-Cl-benzyl)-3-Cl-4-(CF3-phenylamino)-1H-pyrrole2,5-dione. J. Pre-Clinical and Clinical Research, 4 (1), 56-59.

[10] Garmanchuk, L. V., Senchilo, N. V., Nikulina, V. V. et. al. (2011). Cytotoxic in vitro impact of anticancer and antimetastatic agents on tumor cell. Physics of a living being, 19 (2), 51-53.

[11] Kuznietsova H. M., Lynchak O. V., Rybalchenko V. K. et. al. (2013). Effect of dihydropyrrol and maleimide derivatives on the state of the liver and colon in normal rats and those with colorectal carcinogenesis induced by dimethylhydrazine. The Ukrainian Biochemical Journal, 85 (3), 74-84. doi: 10.15407/ ubj85.03.074

[12] Babuta, O. M., Lynchak, O. V., Rybalchenko, V. K. (2013). Histological description of cecum mucosa in rats after exposure to MI-1 and 5-fluorouracil in chemically induced carcinogenesis. Biology and Medicine Issues Bulletin, 1 (102), 31-35. 
[13] Yena M.S., Kuznietsova H.M., Rybalchenko V.K. (2015). Pyrrole Derivatives' Effect on Rats' Colon Mucosa in Experimental Colitis. Research Journal of Pharmaceutical, Biological and Chemical Sciences, 6 (2), 1154-1159.

[14] Lynchak, O. V., Ostrovska, G. V., Rybalchenko V. K. et. al. (2011). Morpho-functional state of the organs of gastro-intestinal tract under the maleimide derivative action during one month. Modern Problems of Toxicology, 1-2, 52-55.

[15] Ross, M. H., Pawlina, W. (2015). Histology: a text and atlas: with correlated cell and molecular biology. LWW, 992.

[16] Bartroff, J., Lai, T. L., Shih, M.-C. (2013). Sequential Experimentation in Clinical Trials. Springer Series in Statistics. doi: 10.1007/978-1-4614-6114-2

[17] Strukov, A. I., Serov, V. V. (2010). Pathological anatomy: The Pupil. Moscow: The Litterra, 848.

[18] Hoshiba, T., Tanaka, M. (2016). Decellularized matrices as in vitro models of extracellular matrix in tumor tissues at different malignant levels: Mechanism of 5-fluorouracil resistance in colorectal tumor cells. Biochimica et Biophysica Acta (BBA) - Molecular Cell Research, 1863 (11), 2749-2757. doi: 10.1016/ j.bbamcr.2016.08.009

[19] Maehara, Y., Oki, E., Saeki, H., Tokunaga, E., Kitao, H., Iimori, M., Niimi, S., Kataoka, Y., Emi, Y., Kakeji, Y., Baba, H., Shirasaka, T. (2016). Evolving 5-Fluorouracil Therapy to Achieve Enhanced Efficacy-Past and Current Efforts of Researchers. Gan To Kagaku Ryoho, 43 (7), 845-854.

[20] Sakai, H., Sagara, A., Matsumoto, K., Hasegawa, S., Sato, K., Nishizaki, M. et. al. (2013). 5-Fluorouracil Induces Diarrhea with Changes in the Expression of Inflammatory Cytokines and Aquaporins in Mouse Intestines. PLoS ONE, 8 (1), e54788. doi: 10.1371/journal.pone.0054788 